\title{
A novel chloro-bridged tetranuclear cadmium(II) cluster with pyridyl- substituted nitronyl nitroxide: structure and magnetic properties
}

\author{
Chin-Jhan Lee ${ }^{\mathrm{a}}$, Ho-Hsiang Wei ${ }^{\mathrm{b}, *}$, Gene-Hsiang Lee ${ }^{\mathrm{c}}$, Yu Wang ${ }^{\mathrm{c}}$ \\ a Deh-Yu College of Nursing and Management, Keelung, Taiwan, ROC \\ b Department of Chemistry, Tamkang University, Tamsui, Taiwan, ROC \\ ' Instrumental Center, College of Science, National Taiwan University, Taipei, Taiwan, ROC
}

Received 1 June 2000; received in revised form 28 August 2000; accepted 9 October 2000

\begin{abstract}
A tetranuclear cadmium(II) complex of 2(2-pyridyl)-4,4,5,5-tetramethyl-4,5-dihydro-1 H-imidazol-1-oxy 3-N-oxide (NIToPy) with $\mathrm{CdCl}_{2},\left[\mathrm{Cd}_{4} \mathrm{Cl}_{8}(\mathrm{NIToPy})_{4}\right]$, has been structurally and magnetically characterized. The structure is based on a novel chlorobridged tetranuclear cadmium quasi-cubane cluster, in which each cadmium atom is chelated by one NIToPy radical, and coordinated with four bridging chlorine atoms. The temperature dependence of the magnetic susceptibility measurements shows a weak ferromagnetic coupling between the radicals. An excellent simulation of the experimental data with the prism type four spins Hamiltonian $H=-2 J_{1}\left(S_{1} S_{2}+S_{2} S_{3}+S_{3} S_{4}+S_{1} S_{4}\right)-2 J_{2} S_{2} S_{4}$ obtained the parameters: $J_{1}=1.12 \mathrm{~cm}^{-1}, J_{2}=-0.20 \mathrm{~cm}^{-1}$, and $g=2.04$. (C) 2000 Elsevier Science S.A. All rights reserved.
\end{abstract}

Keywords: Cadmium compound; Nitronyl nitroxide; Crystal structure; Magnetic properties

When the electron spins of two unpaired electrons are placed in proximity and allowed to interact as in organic radicals, the Columbic repulsion between the two electron spins lifts the zeroth-order degeneracy and gives rise to singlet and triplet states of different total energy for these radical compounds. It has been established that an inter- and/or intra-molecular exchange coupling among the spins and their higher dimensional arrangement in space are required to order them at finite temperature [1]. On the basis of this consideration, the radical centers should have to be placed in proximity in order to have strongly magnetic ordering. Many efforts have been, therefore, devoted to synthesize di-, oligo-, and polyradicals having macroscopic spin alignment with the aids of connecting through the $\pi$-conjugated moieties [2], or complexation with metal ions [2,3].

Diamagnetic metal ions are believed not to mediate magnetic interactions. Several diamagnetic metal complexes with organic radical ligands however, have shown that antiferro- or ferromagnetic interactions were operative through the diamagnetic metal ions; such as alkali

\footnotetext{
${ }^{*}$ Corresponding author. Fax: +886-2-262-09-924.

E-mail address: tkwei@mail.tku.edu.tw (H.-H. Wei).
}

metals [4,5], Ga(III) [6], Ti(IV) [7], $\mathrm{Cu}(\mathrm{I})$ [8], and $\mathrm{Hg}(\mathrm{II})$ [9]. The strength of inter-radical magnetic exchange interactions depends on metal ions and coordination geometries. $\left[\mathrm{M}^{\mathrm{III}}(3,6-\mathrm{dbsq})_{3}\right][6](\mathrm{M}=\mathrm{Al}$, and $\mathrm{Ga} ; 3,6-$ $\mathrm{dbsq}=3,6$-di-tert-butylsemiquinone) and $\left[\mathrm{Ga}^{\mathrm{III}}(3,5-\right.$ dtbsq $\left.)_{3}\right] \quad[6] \quad(3,5$-dtbsq $=3,5$-di-tert-butyl-1,2-benzosemiquinone) showed weak ferromagnetic interactions, while $\left[\mathrm{M}^{\mathrm{IV}}(\mathrm{Cat}-\mathrm{N}-\mathrm{SQ})_{2}\right] \quad(\mathrm{M}=\mathrm{Ti}, \mathrm{Ge}$, and $\mathrm{Sn})$ [7] showed strong ferromagnetic interactions between radical ligands. It is also showed that a copper(I) ion in $[\mathrm{Cu}(\mu-\mathrm{X}) \text { (iminonitroxide) }]_{2}(\mathrm{X}=\mathrm{Br}$ or I) mediates intermolecular ferromagnetic and antiferromagnetic interactions [8b].

Accordingly, if organic radicals are introduced into the bridged cadmium(II) cluster or network, interesting magnetic behaviors might be obtained. Complexes of the type $\mathrm{CdX}_{2}(\mathrm{X}=\mathrm{Cl}$ or $\mathrm{Br})$ with organic bases (e.g., pyridine) typically form one- or three-dimensional halogen-bridged chain or cluster compounds with sixcoordination cadmium(II) [10]. Pyridyl-substituted nitronyl nitroxide, 2(2-pyridyl)4,4,5,5-tetramethyl-4,5-dihydro-1 H-imidazol-1-oxy-3-N-oxide (NIToPy), is a paramagnetic chelate ligand which can mediate a magnetic exchange interaction when bound to paramagnetic transition-metal halides such as $\mathrm{NiCl}_{2}(\mathrm{NIToPy})$ and 
$\mathrm{MnCl}_{2}$ (NIToPy) [11]. Nevertheless, the use of diamagnetic metal ions has not been widespread.

Recently, we have reported that a one-dimensional cadmium(II) complex $\left[\left(\mathrm{CdCl}_{2}\right)_{3}(\mathrm{NIToPy})_{2}\left(\mathrm{C}_{2} \mathrm{H}_{5} \mathrm{OH}\right)_{2}\right]$ revealed a weak antiferromagnetic interaction between two nitroxide radicals [12]. In exploring the cadmium chemistry of organic radicals, we have made the unusual observation that the first example of a novel chlorobridged quasi-cubane cadmium cluster with NIToPy radicals and shows a weak ferromagnetic coupling in the temperature dependence of magnetic susceptibility. The complex $1\left[\mathrm{Cd}_{4} \mathrm{Cl}_{8}(\mathrm{NIToPy})_{4}\right]$ was obtained by dissolving of $\mathrm{CdCl}_{2}$ in methanol and followed by addition of NIToPy [13] in dichloromethane. Dark-blue crystals were formed from the deep blue solution. ${ }^{1}$

The X-ray crystal structure at 298 and $90 \mathrm{~K}$ (Fig. 1) of the complex $\mathbf{1}^{2}$ revealed that the molecule possesses centrosymmetric tetranuclear cluster structure with $\mathrm{Cd}_{4}(\mathrm{Cl})_{2}(\mu-\mathrm{Cl})_{4}\left(\mu_{3}-\mathrm{Cl}\right)_{2}$ core and comprises four NIToPy free radicals. Four cadmium atoms arrange as a prism form in space and there are two different coordination enviroments for the four $\mathrm{Cd}$ atoms, one is formed by the atoms of $\mathrm{O}$ and $\mathrm{N}$ from NIToPy ligand, two $\mu_{3}$ $\mathrm{Cl}$ atoms atoms and two $\mu-\mathrm{Cl}$ atoms such as for $\mathrm{Cd}(1)$, whereas the other one is formed by a chelating NIToPy ligand, one terminal $\mathrm{Cl}$, one $\mu_{3}-\mathrm{Cl}$ atom and two $\mu-\mathrm{Cl}$ atoms such as for $\mathrm{Cd}(2)$. Here, the bond distances and angles of the complex determinated at $90 \mathrm{~K}$ are discussed. The terminal $\mathrm{Cd}(2)-\mathrm{Cl}(4)$ bond distance $[2.488(2) \AA]$ is shorter than the mean $\mathrm{Cd}-\mathrm{Cl}(\mu)$ bond distance [2.592(2) $\AA$ ] and the mean $\mathrm{Cd}-\mathrm{Cl}\left(\mu_{3}\right)$ bond distance $[2.741(2) \AA]$. The shortest intra-molecular $\mathrm{Cd}(1) \cdots \mathrm{Cd}(1 \mathrm{~A})$ separation is $3.800 \AA$. The mean $\mathrm{Cd}-\mathrm{N}$ and $\mathrm{Cd}-\mathrm{O}$ bond distances are 2.416(6) and 2.327(4) $\AA$, respectively. The $\mathrm{O}(1)-\mathrm{N}(2)-\mathrm{C}(6)-\mathrm{N}(3)-\mathrm{O}(2)$ and the $\mathrm{O}(4)-\mathrm{N}(6)-\mathrm{C}(18)-\mathrm{N}(5)-\mathrm{O}(3)$ planes of the nitronyl nitoxide group make dihedral angles of $37.1(2)^{\circ}$ and $31.4(2)^{\circ}$, respectively, with the corresponding pyridine rings. Thus the NO radical groups of NIToPy in the coordination sphere are not in same plane and not in same direction to each other. ${ }^{3}$ The inter-molecular

\footnotetext{
${ }^{1}$ Anal. found: C 34.36; $\mathrm{H}$ 3.86; $\mathrm{N}$ 9.92\%. Calcd. for $\mathrm{C}_{48} \mathrm{H}_{64} \mathrm{Cd}_{4} \mathrm{C}_{18} \mathrm{~N}_{12} \mathrm{O}_{8}$ : C 34.48; H 3.83; N 10.06\%.

${ }^{2}$ Crystal data determinated at $90 \mathrm{~K}$ for 1: $\left[\mathrm{Cd}_{4} \mathrm{Cl}_{8}(\mathrm{NIToPy})_{4}\right]$ : $\mathrm{C}_{48} \mathrm{H}_{64} \mathrm{Cd}_{4} \mathrm{Cl}_{8} \mathrm{~N}_{12} \mathrm{O}_{8}, M=1670.31$, monoclinic, space group $P 2_{1} / n, a=14.4568(1) \AA, \quad b=10.1616(1) \AA, \quad c=21.8609(3) \AA$, $\beta=107.322(1)^{\circ}, V=3065.81(1) \AA^{3}, Z=2$, and $D_{\mathrm{c}}=1.809 \mathrm{~g} \mathrm{~cm}^{-3}$; crystal dimensions $0.32 \times 0.20 \times 0.18 \mathrm{~mm}$. $\lambda(\mathrm{MoK} \alpha)=0.71073 \AA$. The structure was solved by direct methods and Fourier techniques, and refined by full-matrix least-squares on $F^{2}$ using SHELXL-93 (G.M. Sheldrick, University of Göhingen 1993). All non-hydrogen atoms were readily located and refined with anisotropic thermal parameters. The refinement of 362 parameters covered to $R(F)=0.054$ and $R_{\mathrm{w}}\left(F^{2}\right)=0.121$ with $I>2 \sigma(I)$.

${ }^{3}$ The torsion angles for $\mathrm{N}(2)-\mathrm{O}(1)$ vs. $\mathrm{N}(2 \mathrm{~A})-\mathrm{O}(1 \mathrm{~A})$ and $\mathrm{N}(5)$ $\mathrm{O}(3)$ vs. $\mathrm{N}(5 \mathrm{~A})-\mathrm{O}(3 \mathrm{~A})$ are $180^{\circ}$, whereas $\mathrm{N}(2)-\mathrm{O}(1)$ vs. $\mathrm{N}(5 \mathrm{~A})-\mathrm{O}(3 \mathrm{~A})$ and $\mathrm{N}(2 \mathrm{~A})-\mathrm{O}(1 \mathrm{~A})$ vs. $\mathrm{N}(5)-\mathrm{O}(3)$ are $-103.5^{\circ}$ and $103.5^{\circ}$, respectively.
}

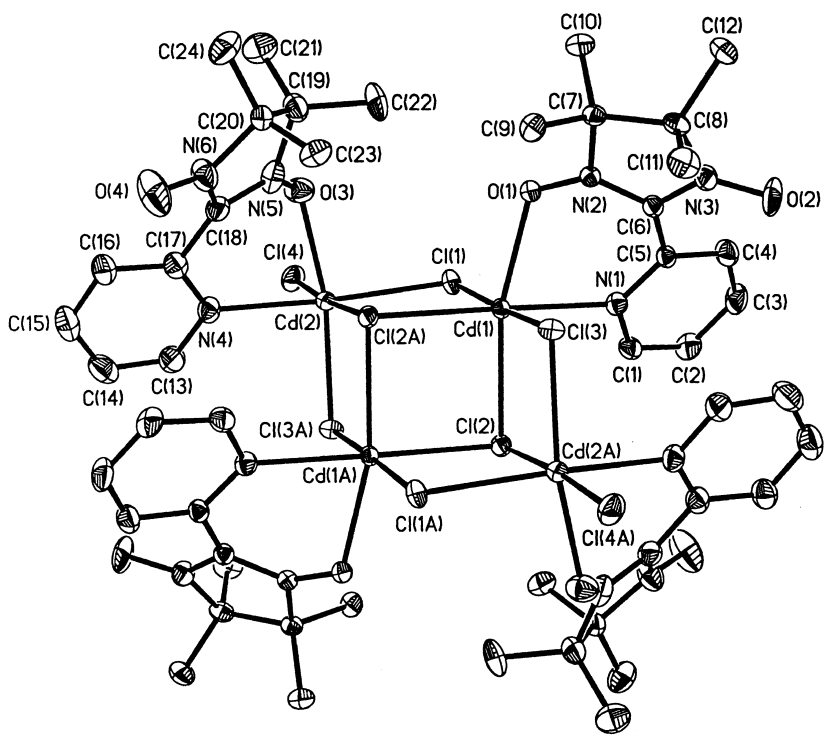

Fig. 1. ORTEP drawing (thermal ellipsoids drawn at the $50 \%$ probability level) of $\left[\mathrm{Cd}_{4} \mathrm{Cl}_{8}(\mathrm{NIToPy})_{4}\right]$ 1. Selected bond distances $(\AA)$ : $\mathrm{Cd}(1)-\mathrm{O}(1)$ 2.326(4), $\mathrm{Cd}(1)-\mathrm{N}(1)$ 2.389(14), $\mathrm{Cd}(1)-\mathrm{Cl}(1)$ 2.586(2), $\mathrm{Cd}(1)-\mathrm{Cl}(2)$ 2.669(2), $\mathrm{Cd}(1)-\mathrm{Cl}(3)$ 2.592(2), $\mathrm{Cd}(2)-\mathrm{O}(3)$ 2.327(3), $\mathrm{Cd}(2)-\mathrm{N}(4)$ 2.444(6), $\mathrm{Cd}(2)-\mathrm{Cl}(4)$ 2.488(2), $\mathrm{Cd}(2)-\mathrm{Cl}(2 \mathrm{~A}) 2.900(2)$, $\mathrm{N}(2)-\mathrm{O}(1)$ 1.303(6), $\mathrm{N}(5)-\mathrm{O}(3)$ 1.279(7). Selected bond angles $\left(^{\circ}\right)$ : $\mathrm{O}(1)-\mathrm{Cd}(1)-\mathrm{Cl}(2)$ 166.08(11), N(1)-Cd(1)-Cl(2A) 177.45(13), $\mathrm{Cl}(3)-$ $\mathrm{Cd}(1)-\mathrm{Cl}(1)$ 175.49(5), O(3)-Cd(2)-Cl(3A) 161.24(13), Cl(4)-Cd(2)$\mathrm{Cl}(2 \mathrm{~A})$ 174.92(4), N(4)-Cd(2)-Cl(1) 162.53(14), $\mathrm{Cd}(1)-\mathrm{Cl}(1)-\mathrm{Cd}(2)$ 101.78(5), $\mathrm{Cd}(1)-\mathrm{Cl}(2)-\mathrm{Cd}(2) 90.51(14), \mathrm{Cl}(1)-\mathrm{Cd}(2)-\mathrm{Cl}(2 \mathrm{~A}) 79.89$ (4), $\mathrm{O}(1)-\mathrm{Cd}(1)-\mathrm{N}(1)$ 76.8(2), $\mathrm{O}(3)-\mathrm{Cd}(2)-\mathrm{N}(4) 76.7(2)$.

closest contact between $\mathrm{O} \cdots \mathrm{O}$ of $\mathrm{NO}$ groups is $4.344(2)$ A.

The X-band EPR spectrum $(9.78 \mathrm{GHz})$ of powder sample at $290 \mathrm{~K}$ exhibits a narrow and shape single signal with $g=2.04$. The temperature dependence of both the product $\chi_{\mathrm{m}} T$ and the molar magnetic susceptibility $\chi_{\mathrm{m}}$ of 1 are represented in Fig. $2 .{ }^{4}$ The $\chi_{\mathrm{m}} T$ value was $1.43 \mathrm{~cm}^{3} \mathrm{~K} \mathrm{~mol}^{-1}$ at $300 \mathrm{~K}\left(\mu_{\text {eff }}=3.38 \mu_{\mathrm{B}}\right)$; on lowering the temperature, the $\chi_{\mathrm{m}} T$ increased, reaching a maximum value of $1.63 \mathrm{~cm}^{3} \mathrm{~K} \mathrm{~mol}^{-1}\left(\mu_{\mathrm{eff}}=3.61 \mu_{\mathrm{B}}\right)$ at $15 \mathrm{~K}$, and then decreased. The maximum $\chi_{\mathrm{m}} T$ value of $1.63 \mathrm{~cm}^{3} \mathrm{~K} \mathrm{~mol}^{-1}\left(\mu_{\mathrm{eff}}=3.61 \mu_{\mathrm{B}}\right)$ that was observed is larger than the non-coupled four $S=1 / 2$ systems $\left(1.5 \mathrm{~cm}^{3} \mathrm{~K} \mathrm{~mol}^{-1}\right)$. The structure of $\mathbf{1}$ consists of four $\mathrm{Cd}$ atoms and four boned-nitroxide oxygens to take a centrosymmetrical prism type arrangement by X-ray analysis. Therefore two ways of theoretical calculations are adopted. We first considered the exchange interaction as the leading term with the corresponding two spins $S_{1}=S_{2}=1 / 2$ of a Hamiltonian $H=-2 J S_{1} S_{2}$ [14]. A poor fit with $J=0.21 \mathrm{~cm}^{-1}$, and an inter-cluster

\footnotetext{
${ }^{4}$ The magnetic susceptibilities of powdered sample of $\mathbf{1}$ were recorded on a Quantum Design model MPMS computer-controlled SQUID magnetometer in the temperature range 4-300 K at a field of $1 \mathrm{~T}$.
} 


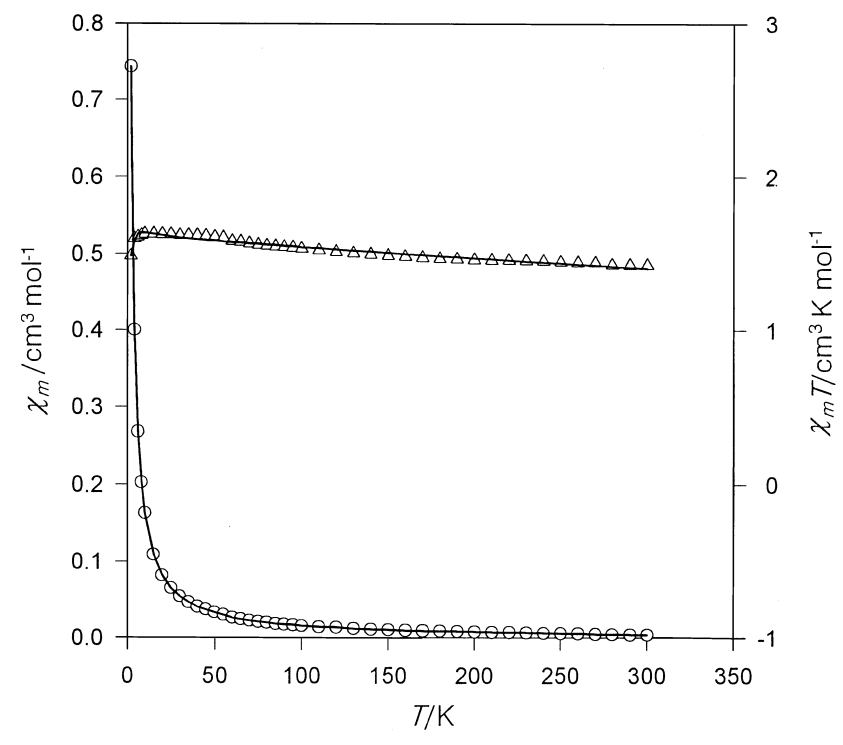

Fig. 2. Plots of $\chi_{\mathrm{m}}(\circ)$ and $\chi_{\mathrm{m}} T(\Delta)$ vs $T$ for crystalline sample of $\mathbf{1}$.

interaction term of $\theta=0$ are obtained. Finally we use a four spins arranged prism model as in the cluster. The spin Hamiltonian $H=-2 J_{1}\left(S_{1} S_{2}+S_{2} S_{3}+S_{3} S_{4}+S_{1} S_{4}\right)$ $-2 J_{2} S_{2} S_{4}$ is adopted [15], where $J_{1}$ and $J_{2}$ are the spin coupling constants between $\mathrm{N}(5)-\mathrm{O}(3) \cdots \mathrm{O}(1)-\mathrm{N}(2)$ and $\mathrm{N}(2)-\mathrm{O}(1) \cdots \mathrm{O}(1 \mathrm{~A})-\mathrm{N}(2 \mathrm{~A})$, respectively. An excellent simulation of the experimental magnetic data is obtained with $J_{1}=1.12 \mathrm{~cm}^{-1}, J_{2}=-0.20 \mathrm{~cm}^{-1}$, and $g=2.04$ (from EPR).

The structural analysis of $\mathbf{1}$ at room temperature and at $90 \mathrm{~K}$ shows that the NO radicals of NIToPy ligands are aggregated in the cadmium cluster, and the directions of NO groups of intra-cluster are not same directions to each other. Therefore, the preliminary mechanistic magnetic interactions in $\mathbf{1}$ can be interpreted to be: (i) the long-range spin polarization effect [16] through the NO-Cd-Cl-Cd-ON framework and spin-polarization through the closest contact between uncoordinated $\mathrm{N}-\mathrm{O}$ groups and hydrogen atoms of the neighbor NIToPy moiety or; (ii) the dipole-dipole interactions between intra- and inter-cluster nitroxide radicals. The decisive mechanism will be discussed elsewhere. The present finding of temperature-dependent magnetic susceptibility revealed that the introduction of diamagnetic metal ion into organic radicals has potentiality for constructing a magnetically ordered molecular system.

\section{Acknowledgements}

The Grant of NSC-88-2113-M-32-010 from National Science Council of Taiwan supported this work.

\section{References}

[1] [a] D.A. Dougherty, Acc. Chem. Res. 24 (1991) 88; [b] H. Iwamura, N. Koga, Acc. Chem. Res. 26 (26) (1993) 346; [c] J.S. Miller, A.J. Epstein, Angew. Chem. Int. Ed. Engl. 32 (1994) 385;

[d] A. Rajca, Chem. Rev. 94 (1994) 871;

[e] O. Kahn, O. Adv. Inorg. Chem. 43 (1995) 179;

[f] K.S. Murry, Adv. Inorg. Chem. 43 (1995) 261.

[2] [a] T. Ishida, H. Iwamura, J. Am. Chem. Soc. 113 (1991) 4238; [b] F. Kanno, K. Inoue, N. Koga, H. Iwamura, J. Phys. Chem. 97 (1993) 13267;

[c] K. Inoue, H. Iwamura, J. Am. Chem. Soc. 116 (1994) 3173;

[d] K. Matsuda, N. Nakamura, K. Takahashi, K. Inoue, N. Koga, H. Iwamura, J. Am. Chem. Soc 117 (1995) 5550;

[e] K. Inoue, T. Hayamizu, H. Iwamura, D. Hashizume, Y. Ohashi, J. Am. Chem. Soc. 118 (1996) 1803;

[f] H. Oshio, M. Umeno, Y. Fukushi, T. Ito, Chem. Lett. (1997) 1065

[g] M. Tanaka, K. Matsuda, T. Itoh, H. Iwamura, J. Am. Chem. Soc. 120 (1999) 7168;

[h] Y.J. Pu, M. Takahashi, E. Tsuchida, H. Nishide, Chem. Lett. (1999) 161;

[i] S. Hayami, K. Inoue, Chem. Lett. (1999) 545.

[3] [a] A. Caneschi, D. Gattechi, P. Rey, Progr. Inorg. Chem. 39 (1991) 331 (and references cited therein);

[b] A. Caneshi, F. Fabrizion, D. Gattechi, P. Rey, R. Sessoli, Inorg. Chem. 30 (1991) 3162;

[c] H.O. Stumpf, Y. Pei, O. Kahn, J. Stetten, J.P. Renard, J. Am. Chem. Soc. 115 (1993) 6738;

[d] F. Hintermaier, K. Sunkel, L.B. Voladarsky, B. Wolfgang, Inorg. Chem. 35 (1996) 5500;

[e] H. Oshio, T. Watanabe, A. Ohto, T. Ikoma, S. Tero-Kubota, Inorg. Chem. 36 (1997) 3014;

[f] F.A. Villamena, M.H. Dickman, D.R. Crist, Inorg. Chem. 37 (1998) 1454.

[4] K. Inoue, H. Iwamura, Chem. Phys. Lett. 207 (1993) 551.

[5] A. Misiolek, R. Huang, B. Kahr, J.E. Jackson, Chem. Commun. (1996) 2119.

[6] D.M. Adams, A.L. Rheinglod, A. Dei, D.N. Hendrickson, Angew. Chem. Int. Ed. Engl. 32 (1993) 391.

[7] [a] A. Caneschi, A. Dei, D. Gatteschi, J. Chem. Soc. Chem. Commun. (1992) 630;

[b] S. Bruni, A. Aneschi, F. Cariati, C. Delfs, A. Dei, D. Gatteschi, J. Am. Chem. Soc. 116 (1994) 1388.

[8] [a] H. Oshio, T. Watanabe, A. Ohto, T. Ito, U. Nagaschima, Angew. Chem. Int. Ed. Engl. 33 (1994) 670;

[b] H. Oshio, T. Watanabe, A. Ohto, T. Ito, H. Masuda, Inorg. Chem. 35 (1996) 472.

[9] C.J. Lee, C.H. Huang, H.H. Wei, Y.H. Liu, G.H. Lee, Yu. Wang, J. Chem. Soc. Dalton Trans. (1998) 171.

[10] [a] R.H. Prince, S.G. Wilkinson, R.D. Gillard, J.A. McCleverty (Eds.), Comprehensive Coordination Chemistry, vol. 5, Pergamon, New York, 1989, p. 925;

[b] S.S. Al-Juaid, H. Buttrus, C. Eaborn, P.B. Hitchcock, J. Smith, K. Tavakkoli, J. Chem. Soc. Chem. Commun. (1988) 1389; [c] A.K. Duhme, H.Z. Strasdeit, Naturforsch. B, 49 (1994) 119; [d] F. Harrms, J. Merle, C. Maichle-Mössbauer, W. Massa, M. Krieger, Inorg. Chem., 37 (1998) 1099.

[11] D. Luneau, G. Risoan, P. Rey, A. Grand, A. Caneschi, D. Gatteschi, J. Laugier, Inorg. Chem. 32 (1993) 5616.

[12] C.F. Hung, H.H. Wei, G.H. Lee, Yu. Wang, Inorg. Chim. Acta. 279 (1998) 233.

[13] P.F. Richardson, R.W. Kreilick, J. Am. Chem. Soc. 99 (1977) 8183. 
[14] The susceptibility data were first fitted by $\chi_{\mathrm{m}}=\left[2 N g^{2} \mu_{\mathrm{B}}^{2} /\right.$ $k(T-\theta)][3+\exp (-2 J / k T)]^{-1}$, given by B. Bleaney, ak.K.D. Bowers, et al., Proc. Roy. Soc. London, Ser. A. 214 (1952) 451.

[15] The resulting expression for the temperature dependence of the magnetic susceptibility is given as: $\chi_{\mathrm{m}}=\left[2 N g^{2} \mu_{B}^{2} / k T\right][A / B]$, $A=1+5 \exp (-2 x)+\exp (2 y)+\exp (2 x), B=3+5 \exp (-2 x)$ $+4 \exp (2 y)+3 \exp (2 x)+\exp (4 x) ; x=-J_{1} / k T, y=-J_{2} / k T$, derived by M.T. Flood, C.G. Barraclough, H.B. Gray, et al., Inorg. Chem. 8 (1969) 193.

[16] [a] H.M. McConnell, J. Chem. Phys. 39 (1963) 1910;

[b] H. Iwamura, Adv. Phys. Org. Chem. 26 (1990) 176;

[c] A. Rajca, Chem. Rev. 94 (1994) 871;

[d] O. Kahn (Ed.), Magnetism: A Supramolecular function; NATO ASI Series, Kluwer Academic Publishers, Dordrecht, The Netherlands, 1996, p. 871. 